\title{
Vibrational mode contribution to the dielectric permittivity of disordered small-molecule organic semiconductors
}

\section{Citation for published version (APA):}

de Vries, X., \& Coehoorn, R. (2020). Vibrational mode contribution to the dielectric permittivity of disordered small-molecule organic semiconductors. Physical Review Materials, 4(8), [085602].

https://doi.org/10.1103/PhysRevMaterials.4.085602

DOI:

10.1103/PhysRevMaterials.4.085602

Document status and date:

Published: 20/08/2020

\section{Document Version:}

Publisher's PDF, also known as Version of Record (includes final page, issue and volume numbers)

\section{Please check the document version of this publication:}

- A submitted manuscript is the version of the article upon submission and before peer-review. There can be important differences between the submitted version and the official published version of record. People interested in the research are advised to contact the author for the final version of the publication, or visit the $\mathrm{DOI}$ to the publisher's website.

- The final author version and the galley proof are versions of the publication after peer review.

- The final published version features the final layout of the paper including the volume, issue and page numbers.

Link to publication

\section{General rights}

Copyright and moral rights for the publications made accessible in the public portal are retained by the authors and/or other copyright owners and it is a condition of accessing publications that users recognise and abide by the legal requirements associated with these rights.

- Users may download and print one copy of any publication from the public portal for the purpose of private study or research.

- You may not further distribute the material or use it for any profit-making activity or commercial gain

- You may freely distribute the URL identifying the publication in the public portal.

If the publication is distributed under the terms of Article 25fa of the Dutch Copyright Act, indicated by the "Taverne" license above, please follow below link for the End User Agreement:

www.tue.nl/taverne

Take down policy

If you believe that this document breaches copyright please contact us at:

openaccess@tue.nl

providing details and we will investigate your claim. 


\title{
Vibrational mode contribution to the dielectric permittivity of disordered small-molecule organic semiconductors
}

\author{
X. de Vries ${ }^{1}$ and R. Coehoorn $\mathbb{1}^{2, *}$ \\ ${ }^{1}$ Department of Applied Physics, Eindhoven University of Technology, P.O. Box 513, NL-5600 MB Eindhoven, The Netherlands \\ ${ }^{2}$ Department of Applied Physics and Institute for Complex Molecular Systems, Eindhoven University of Technology, \\ P.O. Box 513, NL-5600 MB Eindhoven, The Netherlands
}

(Received 20 December 2019; revised 4 June 2020; accepted 24 July 2020; published 20 August 2020)

\begin{abstract}
The functioning of organic optoelectronic devices such as organic light-emitting diodes (OLEDs) is determined in part by the dielectric permittivity $\epsilon$ of the organic materials used, at frequencies that vary from quasistatic to the optical range. The difference between the dielectric constants at these extremes of the frequency scale is due to contributions of vibrational and (for some materials) dipole rotational modes and can depend on the detailed molecular packing. Studies of these contributions are therefore expected to sensitively probe differences in thin-film structures that affect their long-term stability. The absolute value of the dielectric constant affects key processes, such as charge transport, exciton generation, and exciton dissociation. As a first step toward disentangling the various contributions to $\epsilon$, we present in this paper the results of first-principles calculations of the vibrational mode contribution to $\epsilon$ for a large number of small-molecule organic semiconducting materials that are relevant to OLEDs. We find that this contribution is significant for molecules with polar groups and strongly infrared-active vibrational modes, but also for molecules without such groups but with very-low-frequency vibrational modes, below $\sim 2 \mathrm{THz}(\sim 10 \mathrm{meV})$. A comparison with available experimental data reveals good overall agreement concerning the order of magnitude of this contribution, but also indicates the need for detailed material-specific studies of the sensitivity to the thin-film structure.
\end{abstract}

DOI: 10.1103/PhysRevMaterials.4.085602

\section{INTRODUCTION}

The performance of organic optoelectronic devices such as organic light-emitting diodes (OLEDs) and organic photovoltaic (OPV) devices depends sensitively on the frequencydependent dielectric permittivity of the organic semiconductor materials used. At the lower end of the frequency spectrum, under quasistatic measurement conditions, the static relative dielectric constant $\epsilon_{\mathrm{r}, \mathrm{s}}$ determines the space-charge-limited current density $J_{\text {SCLC }}$ in devices in which an intrinsic organic semiconductor is sandwiched between two metallic electrodes that form well-injecting (Ohmic) contacts. The injection of charge carriers is then counteracted by their mutual Coulomb repulsion. Dielectric screening reduces this effect, so $J_{\text {SCLC }}$ increases with increasing $\epsilon_{\mathrm{r}, \mathrm{s}}$. For weakly disordered materials, with a constant mobility, a drift-only theory of $J_{\text {SCLC }}$ yields a value that is proportional to $\epsilon_{\mathrm{r}, \mathrm{s}}$ (Mott-Gurney law [1]). However, for amorphous organic semiconductor materials that are used in optoelectronic devices such as OLEDs, the width of the frontier orbital (shallowest) electron or hole states is in general much larger than the thermal energy. As a result of the relatively strong energetic disorder, the charge carriers are to a certain degree trapped in deep tail states, in particular at low temperatures, leading to an enhanced space charge and an enhanced sensitivity of $J_{\mathrm{SCLC}}$ to $\epsilon_{\mathrm{r}, \mathrm{s}}$. For holes, the density of states (DOS) is often found to be Gaussian,

\footnotetext{
*r.coehoorn@tue.nl
}

whereas the DOS for electrons is often better approximated by a relatively wide exponential distribution function or by a superposition of both types of functions [2,3]. In addition to the intrinsic broadening due to structural disorder, also the presence of (unintentional) extrinsic trap states can contribute to an extended width of the DOS, in particular for frontier orbital energies outside an energy window that is determined by the ionization energy and electron affinity of (unavoidable) water or water-oxygen clusters [4]. For hopping transport in a Gaussian DOS with a width (standard deviation) of $0.1 \mathrm{eV}$, which is a typical value for hole transport, we find from kinetic Monte Carlo simulations a current density of unipolar and bipolar single-layer and multilayer OLEDs that varies as $J_{\mathrm{SCLC}} \propto \epsilon_{\mathrm{r}, \mathrm{s}}^{\alpha}$, with values of $\alpha$ ranging from about 2 at room temperature to more than 5 at $200 \mathrm{~K}$ [5]. A change of $\epsilon_{\mathrm{r}}$ by $15 \%$ can then already lead to a $100 \%$ change of the current density. For hopping transport in sandwich-type devices with an exponential density of states, $J_{\mathrm{SCLC}}$ is proportional to $\epsilon_{\mathrm{r}, \mathrm{s}}^{\alpha}$ [6]. The exponent $\alpha$ is proportional to the width of the DOS and inversely proportional to the absolute temperature, and can already at room temperature be equal to 5 or more for electron transport in organic semiconductors [2].

The dielectric permittivity at optical frequencies affects the light incoupling and outcoupling efficiencies of the microcavity formed by an OLED or OPV device (Ref. [7] and references therein), the radiative decay rate [8], and the Förster resonant energy transfer rates that at least in part determine, e.g., exciton migration, quenching, and annihilation [9]. Furthermore, the dielectric permittivity affects the 


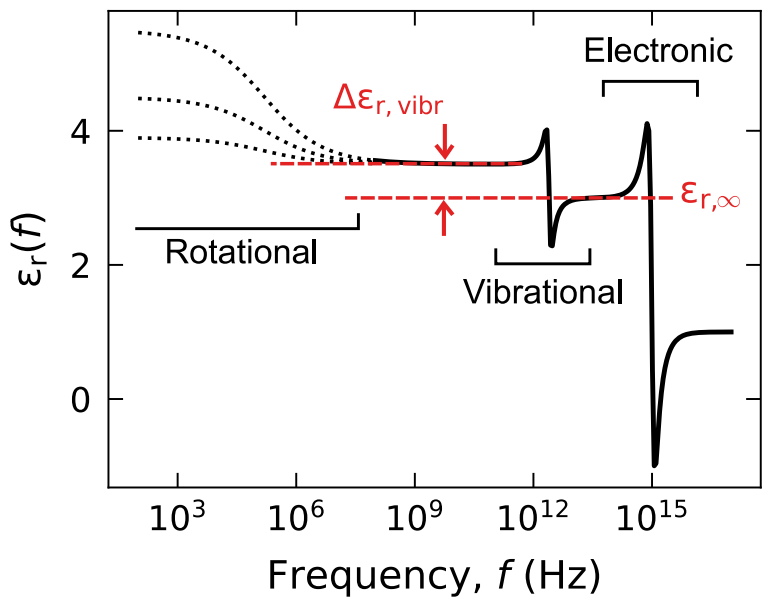

FIG. 1. Frequency dependence of the relative dielectric constant of a typical organic semiconductor material (schematic), defining the vibrational contribution $\Delta \epsilon_{\mathrm{r} \text {, vibr }}$ to the static dielectric constant. For simplicity, the contribution from only one mode is depicted. Rotational contributions (dashed), due to dipole reorientation, depend on the molecular dipole moments and the thin-film packing.

electron-hole Coulomb attraction and hence the exciton generation and dissociation rates. In OPV devices, dielectric screening strongly affects the dissociation probability of chargetransfer state excitons at the donor-acceptor interfaces. This has led to a search for donor and acceptor materials with an enhanced dielectric permittivity $[10,11]$.

The relative dielectric constant is expected to show a frequency $(f)$ dependence as depicted schematically in Fig. 1. The quasistatic relative dielectric constant is larger than the high-frequency value $\epsilon_{\mathrm{r}, \infty}$, measured at frequencies well above the highest vibrational frequency but well below the optically excited electronic modes, due to vibrational and dipole moment rotational modes (change of the magnitude and orientation, respectively, of the molecular dipole moments):

$$
\epsilon_{\mathrm{r}, \mathrm{s}}=\epsilon_{\mathrm{r}, \infty}+\Delta \epsilon_{\mathrm{r}, \mathrm{vibr}}+\Delta \epsilon_{\mathrm{r}, \mathrm{dip}} .
$$

For many small-molecule organic semiconductor materials, the dielectric permittivity at optical frequencies is known from thin-film ellipsometry measurements [12-26], electron energy loss spectroscopy [27], and from theory using quantum-chemically calculated molecular polarizabilities and the Clausius-Mossotti relationship [28,29]. The relative dielectric constant at quasistatic conditions may be obtained from low-frequency capacitance-voltage $(C-V)$ studies of sandwich-type devices [30-39]. In principle, the dielectric permittivity in the full frequency range of interest can be obtained by combining the results of $f$-dependent $C-V$ measurements (dielectric spectroscopy [40]), terahertz, infrared, and optical spectroscopy measurements. However, for disordered organic semiconductors that are used in devices such as OLEDs, a complete view such as given in Fig. 1 is actually at present not available. In particular, no systematic study has so far been made on the vibrational mode contribution to the dielectric permittivity, $\Delta \epsilon_{\mathrm{r}, \mathrm{vibr}}$.

In this paper, we present the results of quantum-chemical calculations of $\Delta \epsilon_{\mathrm{r}, \mathrm{vibr}}$ for a set of 26 small-molecule organic semiconductor materials, and discuss which vibrational modes contribute most strongly. The full names of the selected materials are given in the Appendix (Table II). Our study focuses on materials that are used in OLEDs, such as electron- and hole-transporting materials and fluorescent, metal-organic phosphorescent and thermally activated delayed fluorescence (TADF) emitters. The calculated values of $\Delta \epsilon_{\mathrm{r}, \mathrm{vibr}}$ are based on results from gas-phase vibrational mode calculations, and include the effect on the polarization due to embedding in a film. We consider systems of randomly oriented molecules. The simulations thus neglect the tensor character of the dielectric permittivity that would be obtained in the case of molecular orientation in a thin film, and neglect possible effects resulting from intermolecular interactions.

Our study may be regarded as a first step toward the development of a more complete view on the frequency dependence of the dielectric permittivity, including a possible rotational mode contribution. Recently, the contribution of such modes has attracted much attention. For amorphous organic semiconductor materials that are composed of large molecules with small dipole moments, dipole moment rotation processes are often slow at temperatures well below the glass temperature. A typical example is the polymeric organic semiconductor poly ( $p$-phenylene vinylene) (PPV), which has been used extensively in polymer OLEDs. For the $\mathrm{OC}_{1} \mathrm{C}_{10}$-PPV derivative, dipolar relaxation with a characteristic time of $8.6 \mu \mathrm{s}$ was found, giving rise to a small contribution $\Delta \epsilon_{\mathrm{r} \text {,dip }} \simeq 0.23$ to the relative dielectric constant [41]. The characteristic frequency is well below the lowest vibrational mode frequencies of the order $10^{12} \mathrm{~Hz}$. However, for very small molecules with very large dipole moments, the characteristic response time can be much shorter, and the effect on $\epsilon_{\mathrm{r}, \mathrm{s}}$ can be much larger. For example, camphoric anhydride molecules (CA, static dipole moment $\sim 6 \mathrm{D}$ [42]) embedded in polystyrene (PS) were found to show a picosecond timescale orientational response to the dipolar field of neighboring singlet-excited fluorescent dye molecules [43]. Furthermore, a large increase of $\epsilon_{\mathrm{r}, \mathrm{s}}$ was found, from $\sim 2.4$ (no CA) to $\sim 5.7(24 \mathrm{~mol} \% \mathrm{CA}$ ). Intermediate response times are found for larger molecules. For bis(2-(diphenylphosphino)phenyl)ether oxide (DPEPO, static dipole moment $\sim 8 \mathrm{D}$ [44]), which is frequently used as a host material in TADF-OLEDs, a characteristic orientational response time of about $25 \mathrm{~ns}$ was found when embedded in paraffin [45]. Such solid-state solvation effects affect the emission spectrum of fluorescent emitters $[42,46,47]$ and of TADF emitters $[29,44,45]$. In the case of TADF-systems, these effects are enhanced by the generally large dipole moments of the charge-transfer type singlet and triplet excitons on the TADF emitter molecules [48]. When the characteristic timescale for dipolar orientation is similar to the optical decay time, one can observe a time-dependent blueshift or redshift $[44,45]$. We regard the observation of dipolar rotational mode contributions as an indication that realistic morphologies contain a sizable fraction of free volume that allows rotational and vibrational motion, even though both contributions may be partially constrained due to intermolecular interactions. The simplest situation will arise for films that consist of molecules without a static dipole moment. Combined with experimental values of $\epsilon_{\mathrm{r}, \infty}$ and $\epsilon_{\mathrm{r}, \mathrm{s}}$, our calculational results should then provide a means to judge, using Eq. (1), the possible effect of 
thin-film embedding on $\Delta \epsilon_{\mathrm{r}, \mathrm{vibr}}$. Conversely, a study of dielectric effects may be used to gain improved understanding of the sensitivity of the thin-film morphology on the deposition and postdeposition conditions. It is well known that the properties of evaporated amorphous thin-film materials can depend on the deposition temperature (see, e.g., Ref. [49]), and that in some cases even distinct polyamorphic forms are found [50]. Recently, a significant sensitivity of the morphology to the deposition temperature was found for evaporationdeposited OLEDs [51], as evidenced by a strong dependence of the long-term stability of the emission on the ratio between the deposition temperature and the glass temperature. As the deposition temperature affects the free volume fraction, which in turn can affect the vibrational response of the molecules, one may expect that $\Delta \epsilon_{\mathrm{r}, \mathrm{vibr}}$ depends in part on the deposition conditions. The finding of a relatively large scatter of the experimental values of the static dielectric constant of small-molecule organic semiconductors, obtained by various groups (see Sec. IV of this paper), provides an additional indication of a sensitivity of $\epsilon_{\mathrm{r}}$ to the deposition conditions.

The paper is structured as follows. Section II contains a description of the calculational approach. The total values of $\Delta \epsilon_{\mathrm{r}, \text { vibr }}$ and the cumulative mode-specific contributions are given in Sec. III. In Sec. IV, a comparison is given with the difference between the experimental values of $\epsilon_{\mathrm{r}, \mathrm{s}}$ and $\epsilon_{\mathrm{r}, \infty}$, if available from the literature. Section $\mathrm{V}$ contains a summary and conclusions.

\section{CALCULATIONAL APPROACH}

\section{A. Theoretical method}

As a first step toward the calculation of the vibrational contribution to the quasistatic relative dielectric constant, we calculate the vibrational mode contribution (sometimes called atomic or nuclear contribution) to the polarizability $\alpha_{\text {vibr }} \equiv p / E$, with $p$ the induced dipole moment of the molecule in response to a local electric field $E$. We take the polarizability as an average over all molecular orientations; it is thus treated as a scalar quantity. Within the framework of the Lorentz oscillator model [52], $\alpha_{\text {vibr }}$ may be written as a sum of contributions of all modes $j$,

$$
\alpha_{\mathrm{vibr}}=\frac{\epsilon_{0}}{\pi^{2} N_{\mathrm{A}}} \sum_{j} \frac{n_{j} \Psi_{j}}{v_{j}^{2}},
$$

where $\epsilon_{0}$ is the vacuum dielectric permittivity, $N_{\mathrm{A}}$ is the Avogadro number, $n_{j}$ is the real part of the refractive index at the transition frequency of the mode, $\Psi_{j}$ is the infrared (IR) band area and $v_{j} \equiv f / c$ (with $c$ the speed of light in vacuum) is the spectroscopic wave number. The infrared band area of a mode $j$ is defined as the integral over the corresponding peak in the molar extinction coefficient spectrum for a dilute system, measured as a function of the wave number. See Eq. (S2) of the Supplemental Material (SM) [53]. A derivation of Eq. (2) is given in Sec. S1 of the SM [53]. We note that in Eq. (2) S.I. units are used. In the SM, the appropriate expression that is obtained when using units that are more conventional in the field of IR spectroscopy is given [53]. In Sec. III, we show that it is of interest to compare the IR activity of molecules of different types and sizes by using the average $\bar{\Psi}$ of the IR band area $\Psi_{j}$ over all vibrational modes $j$.

In a nondiluted ("neat") film, with $N$ molecules per $\mathrm{m}^{3}$, the response of each molecule is in part determined by the interaction with the induced electronic and vibrational dipole moments on all other molecules. We include this effect by using the Clausius-Mossotti (CM) relation, leading to

$$
\frac{\epsilon_{\mathrm{r}, \infty}+\Delta \epsilon_{\mathrm{r}, \mathrm{vibr}}-1}{\epsilon_{\mathrm{r}, \infty}+\Delta \epsilon_{\mathrm{r}, \mathrm{vibr}}+2}=\frac{N \alpha_{\mathrm{el}}}{3 \epsilon_{0}}+\frac{N \alpha_{\mathrm{vibr}}}{3 \epsilon_{0}},
$$

with $\alpha_{\mathrm{el}}$ the electronic polarizability, which is related to $\epsilon_{\mathrm{r}, \infty}$ via

$$
\frac{\epsilon_{\mathrm{r}, \infty}-1}{\epsilon_{\mathrm{r}, \infty}+2}=\frac{N \alpha_{\mathrm{el}}}{3 \epsilon_{0}} .
$$

By using the $\mathrm{CM}$ relation, the thin films are approximated as homogeneous and isotropic dielectric materials (see, e.g., Ref. [54] and references therein). Our approach thus neglects the dielectric inhomogeneity that can result from, e.g., positional and orientation disorder, free volume, anisotropic molecular polarizabilities, and the spatially varying polarizability of large molecules that consist of groups of various types.

We have not performed separate calculations of $\alpha_{\mathrm{el}}$. Firstprinciples and machine-learning studies for (mostly) smaller molecules than those studied in this paper suggest that performing electronic polarizability calculations with a sufficient accuracy could soon be within reach [55-61]. Instead, we will use for all materials a value of $n=1.7$, independent of the mode frequency, so $\epsilon_{\mathrm{r}, \infty}=n^{2}=2.89$. Based on the literature overview of experimental data, given in Sec. IV, we regard this as a fair average for the set of materials studied. From Eqs. (3) and (4), $\Delta \epsilon_{\mathrm{r}, \mathrm{vibr}}$ is then given by

$$
\Delta \epsilon_{\mathrm{r}, \mathrm{vibr}}=\left[\frac{\left(n^{2}+2\right)^{2}}{9-\left(n^{2}+2\right) \frac{N \alpha_{\mathrm{vibr}}}{\epsilon_{0}}}\right] \times \frac{N \alpha_{\mathrm{vibr}}}{\epsilon_{0}} .
$$

For many of the materials studied, $\Delta \epsilon_{\mathrm{r} \text {,vibr }}$ will be shown to be much smaller than $\epsilon_{\mathrm{r}, \infty}$. The enhancement factor in between square brackets in Eq. (5) is then close to the limiting value of $\left(n^{2}+2\right)^{2} / 9 \cong 2.66$.

\section{B. Density-functional theory calculations}

We have obtained the normal mode frequencies and the IR band areas from density-functional theory (DFT) with the B3LYP functional [62] and a 6-31G basis set. For the phosphorescent iridium-cored emitters, we used the all-electron SARC-ZORA-SVP basis set for the iridium atom which includes relativistic effects using the zeroth-order regular approximation (ZORA) [63]. In each calculation, the geometry of the molecule was optimized before normal mode calculations were performed. No symmetry restrictions were imposed. For some of the larger molecules, the total energies of two conformers were found to be very close. The insets in Fig. 2 show the lowest-energy conformer, used for calculating $\Delta \epsilon_{\mathrm{r}, \mathrm{vibr}}$. The molecular volumes, needed to calculate the volume density $N$, are taken equal to the van der Waals volumes. These are calculated using the MULTIWFN software [64] with an isosurface of electron density equal to $5 \times 10^{-4} a_{0}^{-3}$, with $a_{0}$ the Bohr radius. This value was chosen to reproduce the 

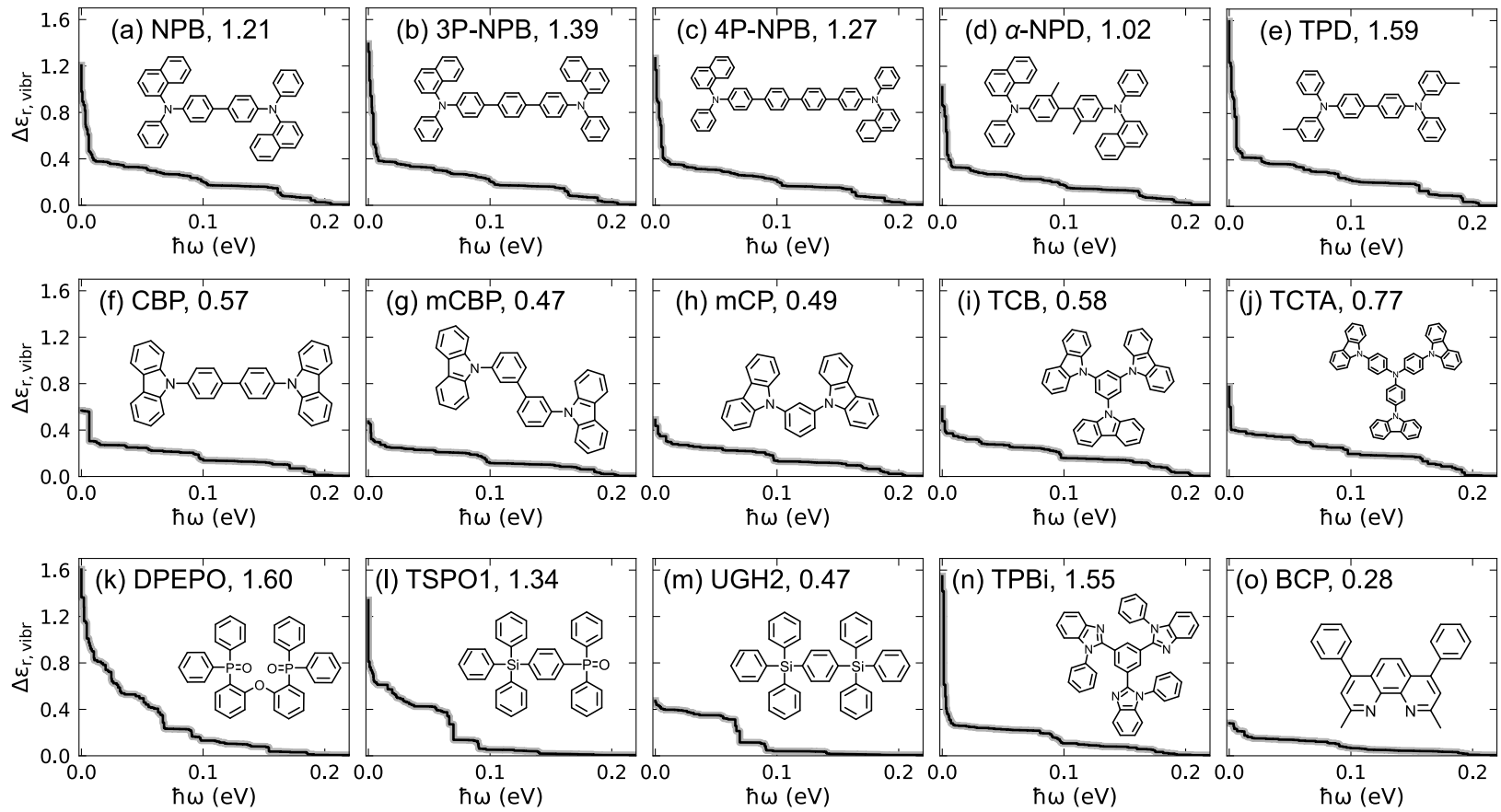

(o) BCP, 0.28

옹
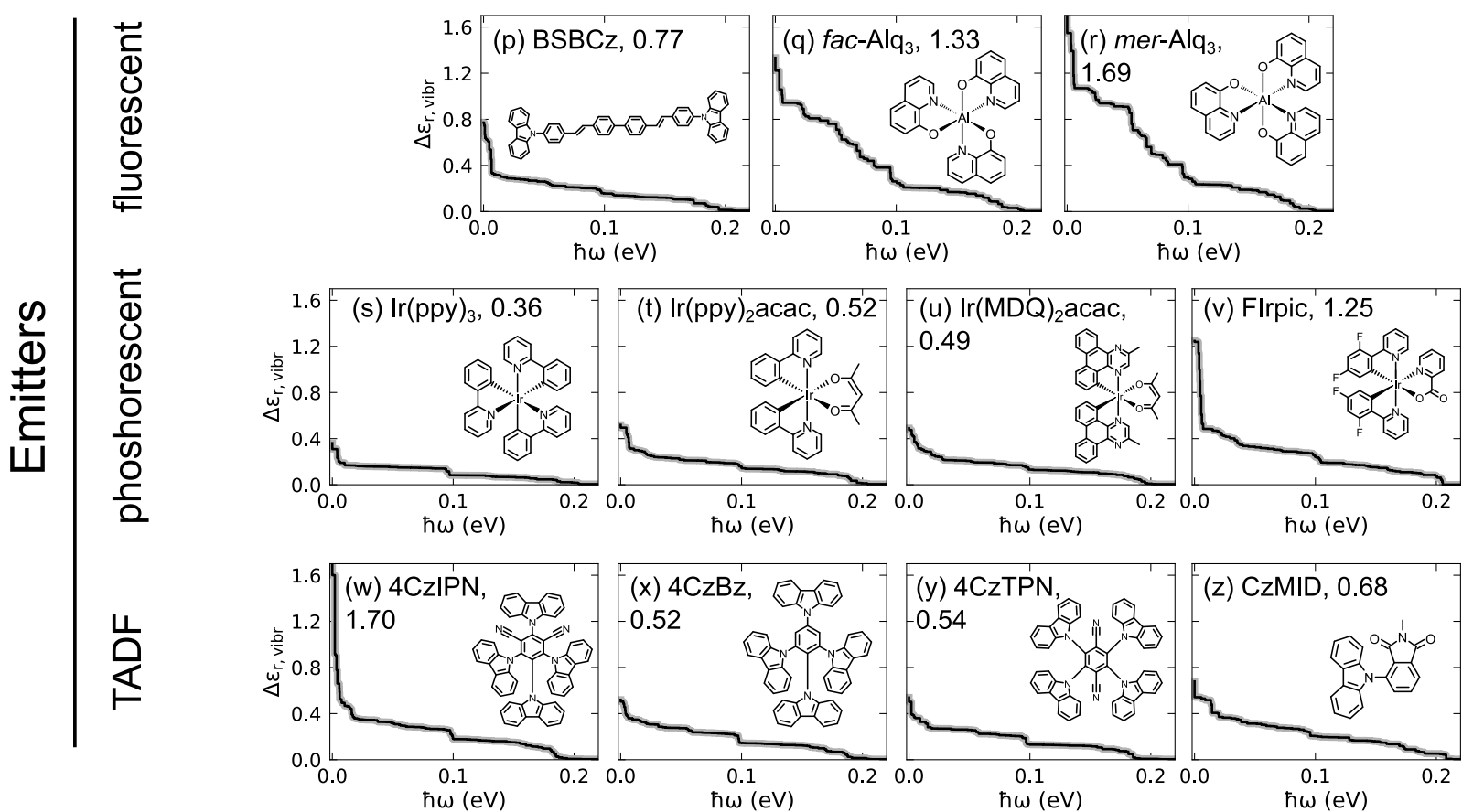

FIG. 2. (a)-(z) Cumulative value of the vibrational contribution to the relative dielectric constant, $\Delta \epsilon_{\mathrm{r}, \mathrm{vibr}}$, calculated for 26 organic semiconductor materials. The full names of the molecules are given in Table II and the molecular structure is shown as an inset. For each material, the total calculated value of $\Delta \epsilon_{\mathrm{r}, \mathrm{vibr}}$ is also given.

experimental densities for various molecules studied in this paper as obtained from Ref. [65] and led for all materials apart from $\mathrm{C}_{60}$ to an agreement within a few percent. For $\mathrm{C}_{60}$, for which the discrepancy was about $30 \%$, we used the experimental thin-film value from Ref. [65]. The IR band areas are calculated within the double harmonic approximation (see, e.g., Refs. [55,66,67]), and give an average over all molecular orientations. Possible thin-film anisotropy effects are thus not included. All methods are available in the ORCA package $[63,68,69]$.

\section{Accuracy of the vibrational energies and IR band areas}

The accuracy of the calculated vibrational energies and IR band areas may be judged from a comparison with results using a different basis set and with results obtained from 
earlier theoretical studies and experimental work. For NPB, we find that the calculated vibrational mode energies and IR band areas as calculated with the 6-31G basis set agree excellently with results obtained using the more extended $6-31 G^{*}$ basis set. We also find that our results agree well with those obtained by Halls et al. from DFT calculations using the GAUSSIAN 98 software tool [66] and the 6-31G* basis set. The value $\Delta \epsilon_{\mathrm{r}, \mathrm{vibr}}=1.27$ that may be deduced from the IR band areas that are given in Ref. [66] is only $6 \%$ larger than the value of 1.20 that is obtained from our study. A comparison between these three results is shown in Sec. S2 of the SM (Fig. S1, Ref. [53]). In Ref. [66], measured thin-film IR absorption spectra are also given. A comparison with our calculational results is given in Fig. S2 of the SM [53]. The peak energies obtained from the DFT calculations in Ref. [66] and in our paper are on average about $3 \%$ and $4 \%$, respectively, larger than the experimental values. This is a well-known discrepancy of DFT calculations using the specific exchange-correlation functional (B3LYP) used. A systematic study for a large number of molecules recommends a scaling factor of 0.9614 [70]. Applying such a scaling factor to our analysis would increase $\epsilon_{\mathrm{r}, \mathrm{vibr}}$ by approximately $8 \%$. However, it is not known whether the IR band intensities also show systematic discrepancies with experiments. For thin films of NPB, a critical comparison with experiment is hampered by the sensitivity of the IR peak intensities to the nonisotropic molecular orientation [66].

Two other well-studied materials are $\mathrm{C}_{60}$ [71-74] and alltrans retinal $[75,76] . \mathrm{C}_{60}$ is of particular interest as it has, because of its high symmetry, only four Ir-active modes [72]. From a comparison with experimental IR absorption spectra for $\mathrm{C}_{60}$, dissolved in a $\mathrm{KBr}$ matrix [74], we find that that our calculated mode energies are, on average, again about $4 \%$ too high. The sum of the IR band areas of the four modes agrees within a few percent with the experimental value, obtained in the $0 \mathrm{~K}$ limit. At room temperature, all IR band areas were found to be smaller, on average by $16 \%$. A fair correlation between calculation and experiment was found when considering the individual IR band areas, as may be seen from Table S1 in the SM. The energy of the lowest Ir-active mode is $\sim 65 \mathrm{meV}$, much larger than for NPB, and the calculated value of $\Delta \epsilon_{\mathrm{r}, \mathrm{vibr}}$ is much smaller, viz. only about 0.04. An overview of these results is given in Sec. S3 of the SM [53].

In Sec. III, we show that the value of $\epsilon_{\mathrm{r}, \mathrm{vibr}}$ contains for many materials strong contributions of low-energy modes, with energies down to $\sim 1 \mathrm{meV}$ (CGS wave number close to $10 \mathrm{~cm}^{-1}$, i.e., a frequency of about $0.3 \mathrm{THz}$ ). For the case of NPB, this was already visible from the cumulative $\epsilon_{\mathrm{r}, \text { vibr }}$ curves shown in Fig. S1. To evaluate the accuracy of the predicted contributions of low-energy modes to $\Delta \epsilon_{\mathrm{r}, \mathrm{vibr}}$, it is of interest to compare the calculationed IR band areas with results of far-IR spectroscopy for molecules with active low-energy modes. For that purpose, we have calculated the vibrational energies and IR band areas for all-trans retinal, the chromophore in the photoactive protein rhodopsin, for which $\mathrm{THz}$ spectroscopy studies have been carried out by Walther et al. [76]. From the elongated shape of the molecule (see Fig. S3(c) in Sec. S4 of the SM [53]), one may expect the presence of low-energy vibrational modes. We indeed find a lowest mode with an energy of only $2.5 \mathrm{meV}$ (CGS wave number $\sim 20 \mathrm{~cm}^{-1}$ ), due to a combined bending and torsion of the molecule around its long axis. IR-absorption and Raman spectroscopy experiments and a DFT study of the mode energies were carried out by Gervasio et al. [75]. A comparison of our results with the results from these two studies, given in Sec. S4 of the SM [53], shows a fair agreement concerning the strongest IR-active absorption peaks at low wave vectors. For our purpose, it is in particular relevant that Walther et al. have also for some of the lowest energy modes (around and below $10 \mathrm{meV}$ ) measured IR band areas of the order $1 \times 10^{3} \mathrm{~m} / \mathrm{mol}$, consistent with our calculational results. That demonstrates that the far-infrared response of such modes is not necessarily strongly constrained by the thin-film embedding.

\section{CALCULATED $\Delta \epsilon_{\mathrm{r}, \text { vibr }}$ FOR OLED MATERIALS}

\section{A. General trends}

Figure 2 shows for a large set of materials that have been used in OLEDs the molecular structure and the calculated cumulative contributions from all modes to $\Delta \epsilon_{\mathrm{r}, \mathrm{vibr}}$. We have grouped the materials studied according to their function in OLEDs to emphasize the diversity of our selection. In Secs. III B and IIIC, we will show that within smaller subsets, useful trends can be discovered when varying structural motifs in small steps. Table I gives the main results of the calculations and the experimental values of the relative dielectric constant that are available from the literature: the calculated values of the mode-averaged IR band area $\bar{\Psi}$, the molecular volume density $N$, the static dipole moment $\mu_{\mathrm{d}}$, the quantity $N \alpha_{\mathrm{vibr}} / \epsilon_{0}$ and $\Delta \epsilon_{\mathrm{r}, \mathrm{vibr}}$, and the experimental values of $\epsilon_{\mathrm{r}, \mathrm{s}}$ and $\epsilon_{\mathrm{r}, \mathrm{opt}}$. The wavelength at which the optical dielectric constant has been obtained is indicated with the references.

The figure reveals a large variability in the calculated values of $\Delta \epsilon_{\mathrm{r}, \mathrm{vibr}}$, ranging from about 0.28 for the relatively small molecule BCP to 1.70 for the TADF emitter 4CzIPN. For most materials, the cumulative value of $\Delta \epsilon_{\mathrm{r}, \mathrm{s}}$ increases gradually below about $0.2 \mathrm{eV}$, down to about $0.01 \mathrm{eV}$. The high-energy $\mathrm{C}-\mathrm{H}$ stretch modes, at about $0.4 \mathrm{eV}$, do not contribute significantly. In the 0.1 to $0.2 \mathrm{eV}$ range, the increase is mainly due to contributions of $\mathrm{C}-\mathrm{C}$ stretch vibrations and $\mathrm{C}-\mathrm{H}$ bending modes in the ring planes. Close to $0.1 \mathrm{eV}$, a distinct contribution due to out-of-plane $\mathrm{C}-\mathrm{H}$ bending modes is visible for many systems. The contributions at smaller energies are to an increasing extent due to modes that involve extended parts of the molecules, including, e.g., torsions and dihedral rotations. Below about $0.01 \mathrm{eV}$, often a much stronger increase is found. For many materials, these modes are found to contribute more than half of the total value of $\Delta \epsilon_{\mathrm{r}, \mathrm{vibr}}$. To quantify their role, Table I includes the value of $\Delta \epsilon_{\mathrm{r}, \mathrm{vibr}}$ that would be obtained when only including modes with an energy larger than $0.01 \mathrm{eV}$.

More in-depth understanding of the cumulative energydependent $\Delta \epsilon_{\mathrm{r}, \text { vibr }}$ curves, shown in Fig. 2, may be obtained from Fig. 3, which gives for each material the calculated normalized cumulative number of vibrational modes, $N_{\text {rel,cum }}(E)$, and the calculated normalized cumulative IR band area, $\Psi_{\text {rel,cum }}(E)$. The figure shows that $N_{\text {rel,cum }}(E)$ is quite similar 
TABLE I. Overview of the simulation results from this paper and of available experimental results for $\epsilon_{\mathrm{r}, \mathrm{s}}$ and $\epsilon_{\mathrm{r}, \mathrm{opt}}$ from the literature. $\bar{\Psi}$ is the IR band area (defined in Sec. II A, see also Eq. (S2) [53]), averaged over all vibrational modes. $N$ is the calculated volume density of molecules, $\mu_{\mathrm{d}}$ is the calculated molecular dipole moment, and $\alpha_{\text {vibr }}$ is the calculated vibrational contribution to the molecular polarizability. $\Delta \epsilon_{\mathrm{r}, \mathrm{vibr}}$ is the calculated vibrational contribution to the relative dielectric constant at low frequencies. The values of $\Delta \epsilon_{\mathrm{r}, \mathrm{vibr}}$ that are obtained by excluding contributions from modes with energies below $10 \mathrm{meV}$ are given in between parentheses. The column $\epsilon_{\mathrm{r}, \mathrm{opt}}$ contains the optical relative dielectric constants that follow from ellipsometry measurements at the wavelengths that are given with the references. Extrapolation to the long-wavelength limit yields estimated values of $\epsilon_{\mathrm{r}, \infty}$ that are $\sim 0.1$ smaller (see the text). The experimental values of the relative electric constant are rounded off to one decimal place, unless (for $\epsilon_{\mathrm{r}, \mathrm{opt}}$ ) separate ordinary (o) and extraordinary (e) values are available. We note that for $\mathrm{Alq}_{3}$, the isomer or the isomer ratio in the thin films studied is not specified in the references to the experimental work given.

\begin{tabular}{|c|c|c|c|c|c|c|c|}
\hline Material & $\begin{array}{c}\bar{\Psi} \\
{\left[10^{3} \mathrm{~m} / \mathrm{mol}\right]}\end{array}$ & $\begin{array}{c}N \\
{\left[10^{3} \mathrm{~mol} / \mathrm{m}^{3}\right]}\end{array}$ & $\begin{array}{c}\mu_{\mathrm{d}} \\
{[\mathrm{D}]}\end{array}$ & $N \alpha_{\text {vibr }} / \epsilon_{0}$ & $\Delta \epsilon_{\mathrm{r}, \mathrm{vibr}}$ & $\epsilon_{\mathrm{r}, \mathrm{s}}$ & $\epsilon_{\mathrm{r}, \mathrm{opt}}$ \\
\hline \multicolumn{8}{|c|}{ Host/transport materials } \\
\hline NPB & 18.7 & 1.94 & 0.26 & 0.36 & $1.21(0.35)$ & $3.3-3.8^{\mathrm{a}}$ & $2.8-2.9^{\mathrm{h}}, 2.96(\mathrm{o}) / 2.82(\mathrm{e})^{\mathrm{i}}$ \\
\hline 3P-NPB & 18.4 & 1.72 & 0.79 & 0.41 & $1.39(0.33)$ & - & - \\
\hline 4P-NPB & 18.0 & 1.57 & 0.36 & 0.38 & $1.27(0.33)$ & - & $3.28^{j}$ \\
\hline$\alpha-\mathrm{NPD}$ & 16.6 & 1.83 & 0.91 & 0.32 & $1.02(0.29)$ & - & - \\
\hline TPD & 20.8 & 2.16 & 0.10 & 0.45 & $1.59(0.39)$ & $3.4^{\mathrm{b}}$ & $2.9^{\mathrm{k}}, 2.82(\mathrm{o}) / 2.76(\mathrm{e})^{\mathrm{i}}, 2.99(\mathrm{o}) / 2.62(\mathrm{e})^{\mathrm{u}}$ \\
\hline CBP & 17.2 & 2.41 & 0.00 & 0.19 & $0.57(0.29)$ & $2.6-2.7^{\mathrm{c}}$ & $2.7^{1}$ \\
\hline $\mathrm{mCBP}$ & 15.3 & 2.42 & 0.76 & 0.16 & $0.47(0.28)$ & - & $3.0^{\mathrm{m}}$ \\
\hline $\mathrm{mCP}$ & 16.7 & 2.90 & 1.33 & 0.17 & $0.49(0.34)$ & - & $3.0^{\mathrm{m}}$ \\
\hline TCB & 19.1 & 2.06 & 0.01 & 0.20 & $0.58(0.33)$ & - & - \\
\hline TCTA & 20.7 & 1.60 & 0.01 & 0.25 & $0.77(0.36)$ & - & $3.0^{\mathrm{m}}$ \\
\hline DPEPO & 15.1 & 2.13 & 5.30 & 0.45 & $1.60(0.79)$ & - & - \\
\hline TSPO1 & 10.8 & 2.12 & 4.94 & 0.40 & $1.34(0.53)$ & - & - \\
\hline $\mathrm{UGH} 2$ & 10.5 & 1.88 & 0.03 & 0.16 & $0.47(0.39)$ & $2.9^{\mathrm{d}}$ & $2.72^{j}$ \\
\hline TPBi & 11.3 & 1.83 & 5.50 & 0.44 & $1.55(0.21)$ & $2.9^{\mathrm{d}}$ & $2.77^{\mathrm{m}}, 2.99(\mathrm{o}) / 2.96(\mathrm{e})^{\mathrm{n}}$ \\
\hline $\mathrm{BCP}$ & 9.7 & 3.18 & 2.87 & 0.10 & $0.28(0.21)$ & $3.5^{\mathrm{d}}$ & $2.8^{\circ}$ \\
\hline \multicolumn{8}{|l|}{ Emitter materials } \\
\hline $\mathrm{BSBCz}$ & 16.7 & 1.70 & 0.08 & 0.25 & $0.77(0.30)$ & - & $3.28(\mathrm{o}) / 2.66(\mathrm{e})^{\mathrm{p}}$ \\
\hline $\mathrm{Alq}_{3}(f a c)$ & 27.9 & 2.81 & 8.99 & 0.39 & $1.33(0.88)$ & $3.0-3.5^{\mathrm{e}}$ & $2.7-2.8^{\mathrm{q}}, 2.75(\mathrm{o})^{1}, 2.82(\mathrm{o}) / 2.82(\mathrm{e})^{\mathrm{i}}$ \\
\hline $\mathrm{Alq}_{3}($ mer $)$ & 29.5 & 2.80 & 4.94 & 0.47 & $1.69(0.95)$ & - & - \\
\hline $\operatorname{Ir}(\mathrm{ppy})_{3}$ & 11.7 & 2.46 & 6.48 & 0.13 & $0.36(0.19)$ & $3.4^{\mathrm{f}}$ & $2.9^{\mathrm{r}}$ \\
\hline $\operatorname{Ir}(\text { ppy })_{2}($ acac $)$ & 17.1 & 2.75 & 2.66 & 0.18 & $0.52(0.31)$ & - & - \\
\hline $\operatorname{Ir}(\mathrm{MDQ})_{2}(\mathrm{acac})$ & 15.6 & 2.00 & 2.69 & 0.17 & $0.49(0.30)$ & - & - \\
\hline FIrpic & 21.0 & 2.69 & 7.27 & 0.37 & $1.25(0.42)$ & - & - \\
\hline $4 \mathrm{CzIPN}$ & 16.7 & 1.59 & 4.00 & 0.47 & $1.70(0.40)$ & - & - \\
\hline $4 \mathrm{CzBz}$ & 16.8 & 1.67 & 0.86 & 0.18 & $0.52(0.34)$ & - & - \\
\hline 4CzTPN & 16.0 & 1.58 & 0.01 & 0.18 & $0.54(0.35)$ & - & - \\
\hline CzMID & 23.2 & 3.77 & 2.35 & 0.22 & $0.68(0.51)$ & - & - \\
\hline \multicolumn{8}{|c|}{ Reference materials } \\
\hline All-trans-retinal & 27.3 & 3.43 & 5.45 & 0.29 & $0.90(0.47)$ & - & - \\
\hline $\mathrm{C}_{60}$ & 1.1 & 1.44 & 0.00 & 0.01 & $0.04(0.04)$ & $4.1 \pm 0.2^{\mathrm{g}}$ & $3.6^{\mathrm{s}}, 3.8 \pm 0.1^{\mathrm{t}}$ \\
\hline
\end{tabular}

${ }^{a}$ Refs. [31-35,38].

${ }^{b}$ Ref. [34].

${ }^{\mathrm{c}}$ Refs. [34,35].

${ }^{\mathrm{d}}$ Ref. [35].

${ }^{\mathrm{e}}$ Refs. $[30,31,35,38]$.

${ }^{f}$ Ref. [34].

${ }^{\mathrm{g}}$ Ref. [96], extrapolated from blends with NPB.

${ }^{\mathrm{h}}$ Refs. $[17,18,20,22]$, at wavelengths $\lambda=1000-1500 \mathrm{~nm}$.

${ }^{i}$ Ref. [97], at $\lambda=1000 \mathrm{~nm}$.

${ }^{\mathrm{j}}$ Ref. [98], at $\lambda=900 \mathrm{~nm}$, assuming an isotropic orientation distribution.

${ }^{\mathrm{k}}$ Ref. [12], at $\lambda=850 \mathrm{~nm}$.

${ }^{1}$ Ref. [16], at $\lambda=1000 \mathrm{~nm}$.

${ }^{\mathrm{m}}$ Ref. [26], at $\lambda=800 \mathrm{~nm}$.

${ }^{\mathrm{n}}$ Ref. [99], at $\lambda=600 \mathrm{~nm}$.

${ }^{\circ}$ Ref. [16], at $\lambda=1000 \mathrm{~nm}$.

${ }^{\mathrm{P}}$ Ref. [100], at $\lambda=1000 \mathrm{~nm}$.

${ }^{\mathrm{q}}$ Refs. [12-15,17-19,22,23], at $\lambda=850-1500 \mathrm{~nm}$.

${ }^{\mathrm{r}}$ Ref. [21], at $\lambda=740 \mathrm{~nm}$.

${ }^{\mathrm{s}}$ Ref. [101] (zero-wavelength extrapolation).

${ }^{\mathrm{t}}$ Ref. [96], at $\lambda=984 \mathrm{~nm}$.

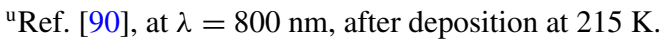



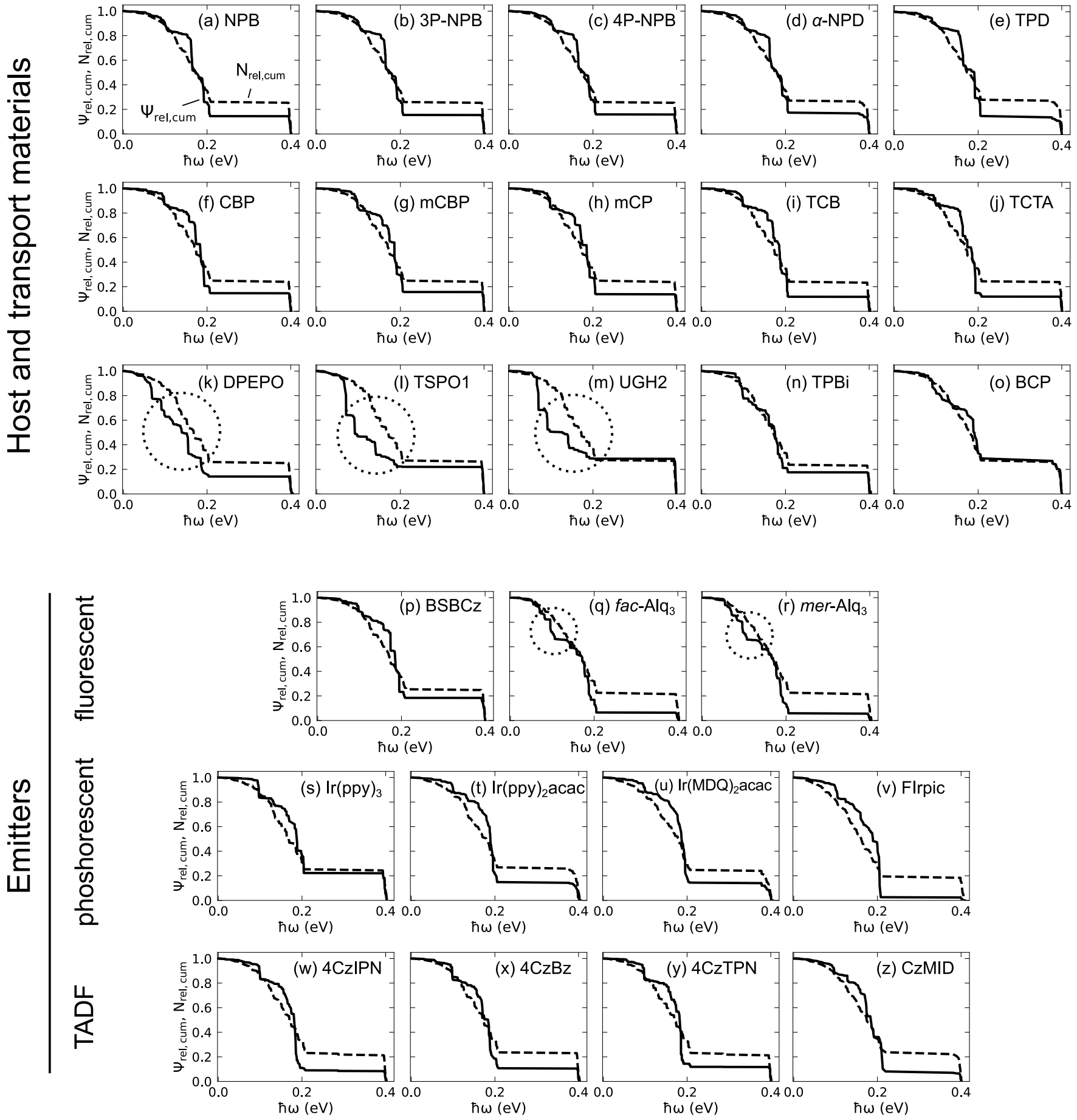

FIG. 3. (a)-(z) Normalized cumulative IR band area $\Psi_{\text {rel,cum }}$ (full curves) and normalized cumulative mode density $N_{\text {rel,cum }}$ (dashed curves), calculated for the 26 organic semiconductor materials considered in this paper. The full names of the molecules are given in Table II and the molecular structures are shown as an inset in Fig. 2. For five materials, the strongest IR-active modes are located at exceptionally small energies (dashed circles).

for all materials. In the next subsection, the nature of some of the characteristic modes will be discussed. Most vibrational modes are located in the $0.1-0.2 \mathrm{eV}$ range. Below $0.1 \mathrm{eV}$, the density of modes is much smaller. Above about $0.2 \mathrm{eV}$, the density of modes shows a gap up to about the energy of C-H stretch modes at about $0.4 \mathrm{eV}$. The figure also shows that the normalized cumulative band area $\Psi_{\text {rel,cum }}(E)$ is more strongly material dependent. Some materials show steep steps, reflect- ing narrow and high peaks in the IR absorption spectrum, while for other materials the curves are more smooth. For most materials, the strongest IR-active modes are located in the $0.1-0.2 \mathrm{eV}$ energy range. However, for five exceptional materials, these modes are distributed more uniformly over the energy range up to $0.2 \mathrm{eV}$ or are even more predominantly located below $0.1 \mathrm{eV}$. In Fig. 3, this is indicated by dashed circles. As all these materials contain relatively heavy 

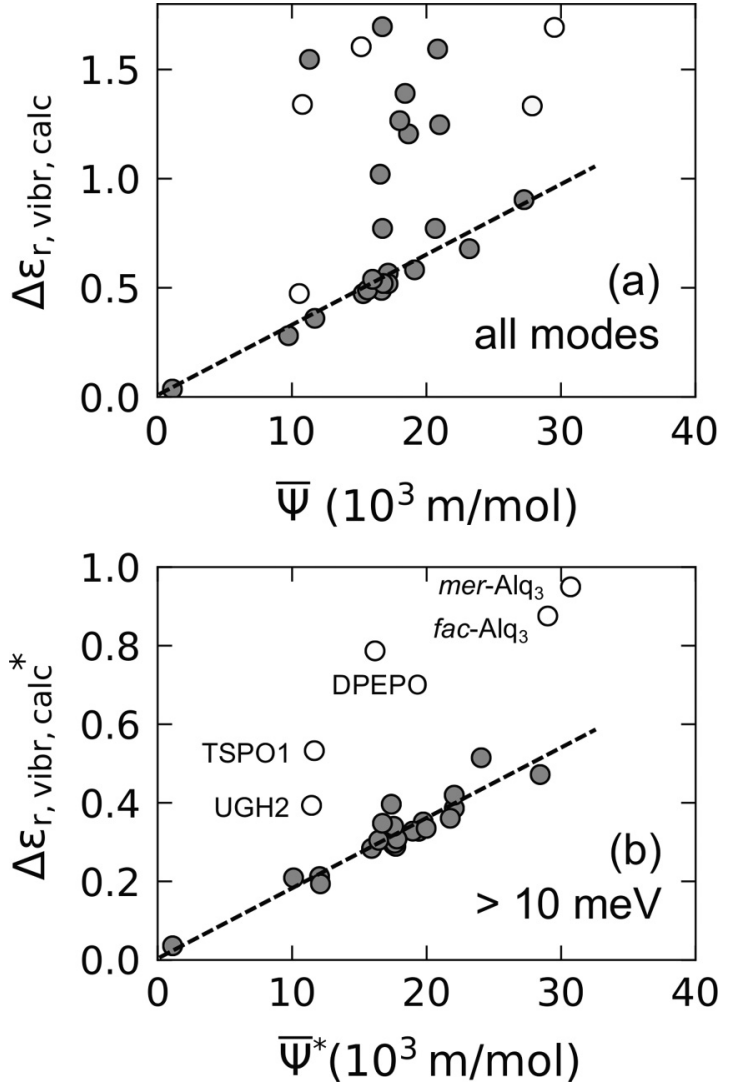

FIG. 4. Dependence of the calculated vibrational contribution to the relative dielectric constant, $\Delta \epsilon_{\mathrm{r}, \mathrm{vibr}, \mathrm{calc}}$, on the mode-averaged value of the infrared band area $\bar{\Psi}$, obtained after including all modes (a) and (indicated with an asterisk) after including only modes with energies larger than $10 \mathrm{meV}$ (b). The numerical values of $\Delta \epsilon_{\mathrm{r} \text {,vibr,calc }}$ and $\bar{\Psi}$ are included in Table I. The materials that in panel (b) do not well follow the main trend (dashed line) are in both panels indicated with an open sphere.

atoms, such as aluminium, silicon, or phosphorus, a plausible explanation of the effect is that the energy of some strongly IR-active modes is reduced by the involvement of atoms with a large mass.

One might expect that, at least as a trend, $\Delta \epsilon_{\mathrm{r}, \text { vibr }}$ increases with increasing average IR band area, $\bar{\Psi}$, which is the average of the IR band area (defined in Sec. II A) over all vibrational modes. The numerical values of $\bar{\Psi}$ are given in the first column of Table I. Figure 4(a) shows that such a trend is indeed visible for a large number of materials (dashed line) but that for various materials $\Delta \epsilon_{\mathrm{r}, \mathrm{vibr}}$ is significantly larger than as expected from the trend line. For most of these exceptional materials, the relatively large value of $\Delta \epsilon_{\mathrm{r}, \mathrm{vibr}}$ is due to contributions from very-low-energy modes, as may be seen from Fig. 4(b). The figure shows the effect of excluding the contributions from modes with energies below $10 \mathrm{meV}$, as indicated with an asterisk. $\bar{\Psi}^{*}$ differs, in general, little from $\bar{\Psi}$, as the fraction of excluded modes is typically only a few percent. However, $\Delta \epsilon_{\mathrm{r} \text { vibr }}{ }^{*}$ is in general smaller than $\epsilon_{\mathrm{r}, \mathrm{vibr}}$ due to the relatively large weight of the excluded lowenergy modes. The figure shows that, apart from only five exceptional cases, $\Delta \epsilon_{\mathrm{r}, \mathrm{vibr}}{ }^{*}$ is excellently correlated with $\bar{\Psi}^{*}$.
These five exceptional materials (indicated by open spheres in Fig. 4), are precisely the materials containing heavy atoms that were already identified in Fig. 3 as materials with strong IR-active modes at relatively low energies (although still well above $0.01 \mathrm{eV}$ ). We thus conclude that the finding of a large calculated value of $\Delta \epsilon_{\mathrm{r}, \mathrm{vibr}}$ can be a result of (i) a strong IR-activity of the molecule (large $\bar{\Psi}$ ), (ii) the presence of verylow energy modes (below $0.01 \mathrm{eV}$ ) that are not exceptionally IR-active but that nevertheless contribute strongly due to their large (inverse-squared-energy) weight [see Eq. (2)], or (iii) the enhanced contribution of strong IR-active modes for materials containing heavy atoms. We have not found a correlation of $\Delta \epsilon_{\mathrm{r}, \mathrm{vibr}}$ with the molecular dipole moment, nor with various other quantities (see Sec. S5 of the SM [53]).

\section{B. OLED host and charge transport materials}

We now analyze in more detail the calculational results for a set of 14 organic semiconductors that have been used as a host material in the emissive layer of OLEDs or as a hole or electron transport layer material. Figures 2(a)-2(e) show the results for NPB and for four similar host molecules, with an added phenyl ring in the core part of the molecule (3P-NPB and 4P-NPB), methylated central phenyl rings $(\alpha-$ NPD), or with adapted outer groups (TPD). For all materials, the energy dependence of the cumulative value of $\Delta \epsilon_{\mathrm{r}, \mathrm{vibr}}$ is similar, and well described by the general trend that was sketched in Sec. III A. The differences in the calculated value of $\Delta \epsilon_{\mathrm{r}, \mathrm{vibr}}$ are mainly due to the lowest-energy modes, below $0.01 \mathrm{eV}$. For the series NPB-3P-NPB-4P-NPB, a small increase of $\alpha_{\text {vibr }}$ with increasing molecular size, which results in a decreasing energy of the lowest energy (chain-bending and torsion) modes, is partially compensated by the effect of the smaller molecular density. The smaller value of $\Delta \epsilon_{\mathrm{r} \text {,vibr }}$ for $\alpha$-NPD than for NPB indicates that the methylation of the two central phenyl groups somewhat hinders these important low-energy modes. For TPD, we obtain a significantly larger value of $\Delta \epsilon_{\mathrm{r}, \mathrm{vibr}}$ than for NPB. We find that the difference is mainly due to the replacement of the naphtyl groups by phenyl groups and that the effect of the methylation of the outer phenyl groups is very small (see Sec. S6 of the SM).

For the carbazole-containing materials shown in Figs. 2(f)2(j), the values of $\Delta \epsilon_{\mathrm{r}, \mathrm{vibr}}$ are significantly smaller than for the materials shown in Figs. 2(a)-2(e). The figures show that the difference is almost entirely due to low-energy modes, below $0.01 \mathrm{eV}$. We find that this can be explained from the larger stiffness of the carbazole end groups as compared to the more flexible di-phenyl or phenyl/naphtyl end groups of molecules (a)-(e). For NPB and CBP, e.g., the average energy of the lowest ten modes is $3.9 \mathrm{meV}$ and $6.9 \mathrm{meV}$, respectively, whereas for these modes the average IR band area is for both materials almost equal $\left(\sim 0.7 \times 10^{3} \mathrm{~m} / \mathrm{mol}\right)$. Also for these carbazole-based materials, $\Delta \epsilon_{\mathrm{r}, \mathrm{vibr}}$ tends to increase with increasing molecular size, as may be seen from a comparison between the results for the small molecule $\mathrm{mCP}$ and the larger molecule TCTA.

Figures 2(k) and 2(l) give the results for two organic semiconductors with phosphine oxide $(\mathrm{P}=\mathrm{O})$ bonds, DPEPO and TSPO1, respectively. These materials have been used as a host for blue phosphorescent OLEDs and TADF-OLEDs, in 
view of their high triplet energies. Furthermore, their polarizability is used to obtain a decreased energy gap between the charge-transfer-type singlet and triplet exciton states of TADF emitters [77-79]. Both materials show comparatively small contributions to $\Delta \epsilon_{\mathrm{r}, \mathrm{vibr}}$ in the $0.1-0.2 \mathrm{eV}$ range, and a strong increase of such contributions below $0.1 \mathrm{eV}$. For DPEPO, the cumulative value of $\Delta \epsilon_{\mathrm{r}, \mathrm{vibr}}$ is already at an energy of $0.01 \mathrm{eV}$ more than twice the typical value obtained for materials (a)-(j). The important contribution of the $\mathrm{P}=\mathrm{O}$ bonds (two for DPEPO) is evident from the comparison with TSPO1 (one $\mathrm{P}=\mathrm{O}$ bond) and with the otherwise similar high-triplet-gap material $\mathrm{UGH} 2$ [80] without $\mathrm{P}=\mathrm{O}$ bonds, for which only a small low-energy contribution to $\Delta \epsilon_{\mathrm{r} \text {,vibr }}$ is found [Fig. 2(m)]. The largest contribution to the value of $\Delta \epsilon_{\mathrm{r}, \mathrm{vibr}}$ of UGH2 is due to vibrational modes at about $70 \mathrm{meV}$ that involve the two Si atoms. TPBi [see Fig. 2(n)] has been used intensively as an electron-transporting material and as a host material for fluorescent and phosphorescent dopants (see, e.g., Ref. [81] and references therein). Interestingly, the cumulative value of $\Delta \epsilon_{\mathrm{r}, \mathrm{vibr}}$ at $0.01 \mathrm{eV}$ is smaller than for all previously discussed materials whereas, on the other hand, there are very strong contributions below $0.01 \mathrm{eV}$. We find that this effect is due to a low-energy vibrational response of the polar ligands. BCP [see Fig. 2(o)] has a very deep HOMO energy and has therefore been used intensively as an electron transport and hole-blocking layer in OLEDs [82]. The small size and the relatively rigid core lead to $\Delta \epsilon_{\mathrm{r}, \mathrm{vibr}}=0.28$, which is the smallest value that we have obtained for the set of materials studied.

\section{OLED emitter materials}

Two fluorescent emitter materials are included in our study: BSBCz [Fig. 2(p)], a blue-green emitter with a near-100\% photoluminescence quantum efficiency when embedded as a dilute guest in CBP [83] that has recently been utilized as the active semiconductor in devices showing evidence of current-induced lasing [84] and $\mathrm{Alq}_{3}$, a prototypical metalorganic emitter and electron transport material [85]. For $\mathrm{BSBCz}$, the energy-dependent $\Delta \epsilon_{\mathrm{r}, \mathrm{vibr}}$ function is quite similar to that for the carbazole-based systems (f)-(j). The contribution of the low-energy bending/torsion modes below $0.01 \mathrm{eV}$ is relatively large as a result of the elongated shape of the molecule. For $\mathrm{Alq}_{3}$, calculations have been done for the facial and meridional isomers [Figs. 2(q) and 2(r)]. For mer-Alq ${ }_{3}$, we find the second-largest value of $\Delta \epsilon_{\mathrm{r}, \text { vibr }}$ for the set of materials studied, viz. 1.69. Remarkably, for both isomers, $\Delta \epsilon_{\mathrm{r}, \mathrm{vibr}}$ is already quite large if only contributions of modes above $0.01 \mathrm{eV}$ are included. As for DPEPO, this is due to vibrations involving the strongly polar ligands.

Of all phosphorescent systems considered, the green phosphorescent emitter $\operatorname{Ir}(\mathrm{ppy})_{3}$ shows the smallest value of $\Delta \epsilon_{\mathrm{r}, \text { vibr }}$, viz. 0.36 [Fig. 2(s)]. The molecule has a highly symmetric facial structure and the ligands are only weakly polar. For the less symmetric yellow-green and orange emitter molecules $\operatorname{Ir}(\mathrm{ppy})_{2}(\mathrm{acac})$ and $\operatorname{Ir}(\mathrm{MDQ})_{2}(\mathrm{acac})$, the value of $\Delta \epsilon_{\mathrm{r}, \text { vibr }}$ is found to be somewhat larger [Figs. 2(t) and 2(u)]. For the sky-blue emitter FIrpic, with strongly polar ligands, a large value of $\Delta \epsilon_{\mathrm{r}, \mathrm{vibr}}=1.25$ is found [Fig. 2(v)].
The effect of polar ligands is also evident when comparing various types of TADF emitters. Within the set of materials included in this study, the largest value of $\epsilon_{\mathrm{r} \text {,vibr }}$ is obtained for the prototypical green TADF emitter 4CzIPN [86-88], viz. 1.70 [Fig. 2(w)]. From a comparison with 4CzBZ [86], in which the polar $\mathrm{C}=\mathrm{N}$ groups have been replaced by hydrogen and with 4CzTPN [86], in which the $\mathrm{C}=\mathrm{N}$ groups are connected at symmetric (para) positions to the central phenyl ring [Figs. 2(x) and 2(y)], it is evident that the large value of $\epsilon_{\mathrm{r}, \mathrm{vibr}}$ for $4 \mathrm{CzIPN}$ is due to vibrational modes that involve the $\mathrm{C}=\mathrm{N}$ groups. For the carbazole-based green emitter molecule CzMID that has been used in a recent study on the operational lifetime of TADF-OLEDs [88], a similar value of $\Delta \epsilon_{\mathrm{r}, \mathrm{vibr}}$ $(0.68)$ is obtained [Fig. 2(z)].

\section{COMPARISON WITH EXPERIMENT}

In the last two columns of Table I, the experimental values of the static and long-wavelength optical relative dielectric constant, $\epsilon_{\mathrm{r}, \mathrm{s}}$ and $\epsilon_{\mathrm{r}, \mathrm{opt}}$, respectively, are given, if available, from the literature. The static values have in all cases been obtained from $C-V$ measurements of sandwich-type devices, typically at frequencies in the $10^{2}-10^{5} \mathrm{~Hz}$ range. The $\epsilon_{\mathrm{r}, \mathrm{opt}}$ column gives the optical values that are measured using ellipsometry at the wavelengths given in the references at the bottom of the table. Extrapolation to an infinite wavelength using, e.g., the Cauchy relation leads to a reduction of a few percent with respect to the value at $\lambda=1000 \mathrm{~nm}$. We expect that the values of $\epsilon_{\mathrm{r}, \infty}$ are generally $\delta \sim 0.05-0.15$ smaller than $\epsilon_{\mathrm{r}, \mathrm{opt}}$. In analyzing the results of ellipsometry experiments, from which the high-wavelength values are deduced, a distinction is often made between the ordinary (o) and extraordinary (e) values of the refractive index. If available, these separate values are included in the table. The strong optical anisotropy that is observed for some molecules, such as NPB and BSBCz, reflects a nonisotropic orientation distribution of these molecules with the long axis oriented preferentially parallel to the film plane. For other molecules, such as TPBi and $\mathrm{Alq}_{3}$, with a less elongated shape, almost no anisotropy has been observed. In $C-V$ measurements probing $\epsilon_{\mathrm{r}, \mathrm{s}}$, the electric field is directed perpendicular to the film plane. The static dielectric permittivity should therefore be compared with the extraordinary component of the optical permittivity tensor. The experimental difference between the static and the high-frequency relative dielectric constant is therefore

$$
\Delta \epsilon_{\mathrm{r}, \exp }=\epsilon_{\mathrm{r}, \mathrm{s}}-\left(\epsilon_{\mathrm{r}, \mathrm{opt}, \mathrm{e}}-\delta\right) .
$$

We will take $\delta$ equal to 0.1 .

Figure 5(a) gives a comparison of $\Delta \epsilon_{\mathrm{r}, \exp }$ with the calculated values of the vibrational contribution to $\Delta \epsilon_{\mathrm{r}}$, for the nine materials for which experimental data are available from Table I. The materials with a large dipole moment (see Table I) are indicated with bold lettering. The error bars are based on the uncertainties that follow from the range of experimental values given in the table, but do not include the uncertainties related, e.g., to measurement inaccuracies, possible structural differences of the thin films that were used in the $C-V$ and the ellipsometry experiments, the effects of a varying optical anisotropy, and the uncertainty in the correction term $\delta$. For 


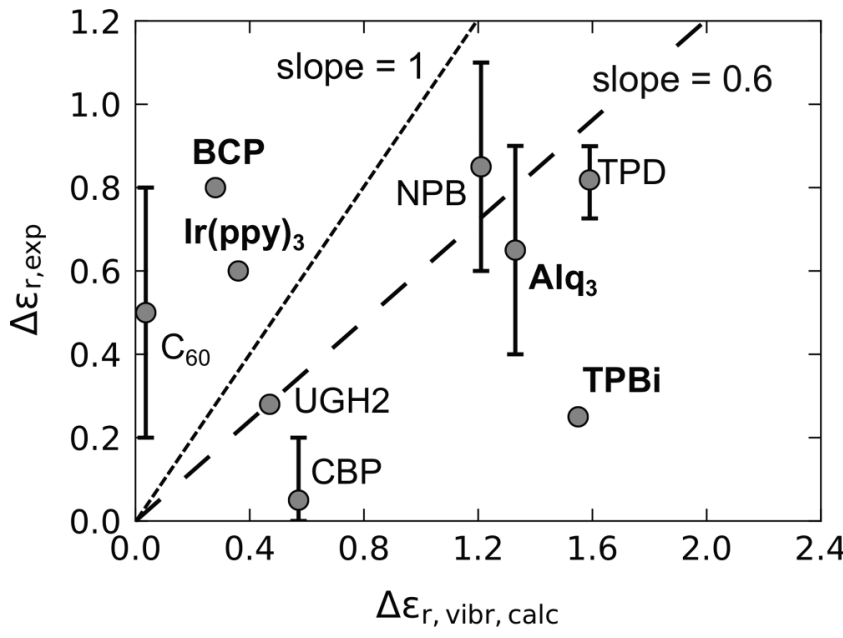

FIG. 5. Comparison of the experimental $\left(\epsilon_{\mathrm{r}, \exp }=\Delta \epsilon_{\mathrm{r}, \mathrm{s}}-\epsilon_{\mathrm{r}, \infty}\right)$ and calculated $\left(\Delta \epsilon_{\mathrm{r}, \mathrm{vibr}, \mathrm{calc}}\right)$ vibrational contribution to the dielectric constant for those materials for which $\Delta \epsilon_{\mathrm{rexp}}$ can be deduced from the data given in Table I. Extrapolation to the long-wavelength limit has been used to obtain estimated values of $\epsilon_{\mathrm{r}, \infty}$ from the experimental optical dielectric constant and yields values that are approximately 0.1 smaller than the experimental values of $\epsilon_{\mathrm{r} \text {,opt }}$ given in Table I (see the text). The error bars are only based on the variation of the published experimental data and do not include other contributions (see the text). Materials with large molecular dipole moments are indicated with bold lettering. The long-dashed line indicates the trend when only considering the data for the intensively studied materials NPB, $\mathrm{Alq}_{3}$, and TPD.

the three most intensively studied materials, NPB, TPD, and $\mathrm{Alq}_{3}$, various studies have indicated the relevance of complicating thin-film effects. For NPB, the finding of a wide range of experimental values of $\epsilon_{\mathrm{r}, \mathrm{s}}$ could be a result of varying deposition conditions such as the deposition temperature, leading, e.g., to a varying molecular packing density and a varying degree of molecular orientation [89]. Such effects were also found for TPD [90]. For $\mathrm{Alq}_{3}$, the references cited give no details on the isomeric composition of the $\mathrm{Alq}_{3}$ films (facial or meridional). The value of $\Delta \epsilon_{\mathrm{r}, \text { vibr,calc }}$ used in the figure refers to the facial isomer. However, Table I shows that the calculated value for the meridional isomer is somewhat larger. We also note that from thin-film studies various polycrystalline phases of $\mathrm{Alq}_{3}$ have been identified [91]. Upon deposition, a transformation could occur between the two isomers, depending on the substrate temperature [92]. A significant dependence of $\epsilon_{\mathrm{r} \text {,opt }}$ (from about 2.7 to 3.3) on the deposition temperature and the relaxation time after deposition has been found [13].

The figure reveals that for most materials, $\Delta \epsilon_{\mathrm{r}, \exp }$ is clearly positive, as expected. However, only a weak correlation with the calculated values is found. The results for the three most intensively studied materials, NPB, TPD, and $\mathrm{Alq}_{3}$, suggest that the calculations overestimate $\Delta \epsilon_{\mathrm{r}, \mathrm{vibr}}$ by approximately a factor of $1.5-2$. The long-dashed line, with a slope equal to 0.6 , provides a fair fit to the data for $\mathrm{NPB}, \mathrm{Alq}_{3}, \mathrm{TPD}$, and UGH2. The finding of a reduced value of $\Delta \epsilon_{\mathrm{r}, \mathrm{vibr}}$ could be due to a decrease of the IR band areas with increasing temperature, such as found from experiment for $\mathrm{C}_{60}$ (see Sec.
S3 of the SM [53]). In particular, one might ask to what extent structural constraints in a film might reduce the contribution at room temperature from the lowest-energy modes. From the $\mathrm{THz}$ studies of very-low-energy modes in retinal, discussed in Sec. II C, it follows that contributions from such modes are still visible at room temperature, although they are strongly damped. A strong increase of the damping of low-energy modes with increasing temperature was also observed from $\mathrm{THz}$ studies of various nucleobases [93] and aminoacids [94].

For the materials with a large dipole moment (BCP, $\operatorname{Ir}(\mathrm{ppy})_{3}, \mathrm{Alq}_{3}$, and TPBi), we cannot exclude the presence of a rotational contribution to $\Delta \epsilon_{\mathrm{r}}$. That could explain the relatively large experimental value of $\Delta \epsilon_{\mathrm{r}}$ for $\mathrm{BCP}$ and $\operatorname{Ir}(\mathrm{ppy})_{3}$. However, the experimental value is for TPBi much smaller than the calculated value. In contrast to the three other materials with large dipole moments, we found for TPBi that very-low-energy modes contribute strongly. We speculate that in the case of low-energy vibrations of groups with large dipole moments, local orientational correlations may lead to a enhanced collective response of many molecules or to a reduced (frustrated) response, depending on the type of correlation. It would therefore be of interest to extend firstprinciples studies of dipole moment orientation distributions in organic semiconductors [95] to include a study of such effects.

For $\mathrm{C}_{60}$, the difference between the calculated and experimental values is quite remarkable. In Sec. S3 of the SM [53], the calculated IR band areas show a fair agreement with the experimental values, providing support for the small calculated value $\left(\Delta \epsilon_{\mathrm{r}, \mathrm{vibr}, \mathrm{calc}}=0.04\right)$. The finding of a much larger experimental value indicates that the actual uncertainty of $\Delta \epsilon_{\mathrm{r} \text { exp }}$ is, at least for $\mathrm{C}_{60}$, much larger than as indicated in the figure. We conclude that the set of available experimental data at present does not yet allow an in-depth assessment of the validity of the calculational approach. It would not only be of interest to extend the set of materials studied, but also to investigate the sensitivity of the experimental results to the deposition conditions, the film thickness, and the measurement temperature.

\section{SUMMARY AND CONCLUSIONS}

We have calculated the vibrational contribution to the relative dielectric constant for a large set of organic semiconductor materials that have been used in OLEDs using a DFT-based first-principles approach. The calculations predict values of $\Delta \epsilon_{\mathrm{r}, \mathrm{vibr}}$ that tend to increase with increasing IR activity of the molecule, i.e., with an increasing value of the mode-averaged IR band area $(\bar{\Psi})$. Particularly large values are also found in the presence of very-low energy modes (below $0.01 \mathrm{eV}$ ), even if these are not exceptionally IR active, and for materials that contain heavy atoms that are involved in strong Ir modes. The two latter effects are due to the large (inversesquared-energy) weight of low-energy modes, as expressed by Eq. (2). Whereas the dielectric constant at optical frequencies for most materials is around 3, the calculations predict values of $\Delta \epsilon_{\mathrm{r}, \mathrm{vibr}}$ up to about 1.7. A comparison with available experimental data from the literature suggests that the calculations somewhat overestimate the effect. For the three most intensively experimentally studied materials, NPB, TPD, and $\mathrm{Alq}_{3}$, 
TABLE II. Full names of the materials studied in this paper, in the order of appearance in Figs. 2 and 3 and Table I.

\begin{tabular}{|c|c|}
\hline Material & Full name \\
\hline NPB & $N, N^{\prime}$-bis(naphthalen-1-yl)- $N, N^{\prime}$-bis(phenyl)-benzidine \\
\hline 3P-NPB & 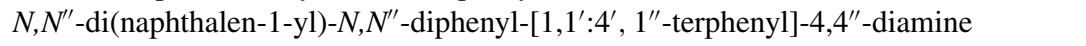 \\
\hline $4 \mathrm{P}-\mathrm{NPB}$ & $N, N^{\prime}$-di-1-naphthalenyl- $N, N^{\prime}$-diphenyl $\left[1,1^{\prime}: 4^{\prime}, 1^{\prime \prime}: 4^{\prime \prime}, 1^{\prime \prime \prime}\right.$-quaterphenyl $]-4,4^{\prime \prime \prime}$-diamine \\
\hline$\alpha-\mathrm{NPD}$ & $N, N^{\prime}$-bis(naphten-1-yl)-N,N'-bis(phenyl)-2, 2'-dimethylbenzidine \\
\hline TPD & $N, N^{\prime}$-bis(3-methylphenyl)- $N, N^{\prime}$-diphenylbenzidine \\
\hline $\mathrm{CBP}$ & $4,4^{\prime}$ - $N, N^{\prime}$-dicarbazole-1, $1^{\prime}$-biphenyl \\
\hline $\mathrm{mCBP}$ & 3,3-di(9H-carbazol-9-yl)biphenyl \\
\hline $\mathrm{mCP}$ & 1,3-bis $(N$-carbazolyl)benzene \\
\hline TCB & $1,3,5$-tri $(N$-carbazolyl)benzene \\
\hline TCTA & tris(4-carbazoyl-9-ylphenyl)amine \\
\hline DPEPO & bis[2-(diphenylphosphino)phenyl] ether oxide \\
\hline TSPO1 & diphenyl[4-(triphenylsilyl)phenyl]phosphine oxide \\
\hline UGH2 & $p$-bis(triphenylsilyl)benzene \\
\hline TPBi & $2,2^{\prime}, 2^{\prime \prime}-(1,3,5$-benzinetriyl)-tris(1-phenyl-1- $H$-benzimidazole $)$ \\
\hline $\mathrm{BCP}$ & 4,7-diphenyl-2,9-dimethyl-1,10-phenanthroline (bathocuproine) \\
\hline $\mathrm{BSBCz}$ & $4,4^{\prime}$-bis $[(N$-carbazole $)$ styryl $]$ biphenyl \\
\hline $\mathrm{Alq}_{3}(f a c, m e r)$ & tris-(8-hydroxyquinoline)aluminum \\
\hline $\operatorname{Ir}(\mathrm{ppy})_{3}$ & tris[2-phenylpyridinato- $\left.\mathrm{C}^{2}, \mathrm{~N}\right]$ iridium(III) \\
\hline $\operatorname{Ir}(\mathrm{ppy})_{2}(\mathrm{acac})$ & bis[2-(2-pyridinyl-N)phenyl-C](acetylacetonato)-iridium(III) \\
\hline $\operatorname{Ir}(\mathrm{MDQ})_{2}(\mathrm{acac})$ & bis(2-methyldibenzo[f,h]quinoxaline)(acetylacetonate)iridium(III) \\
\hline FIrpic & bis[2-(4,6-difluorophenyl)pyridinato- $\left.{ }^{2}, \mathrm{~N}\right]$-(picolinato)-iridium(III) \\
\hline 4CzIPN & 1,2,3,5-tetrakis(carbazol-9-yl)-4,6-dicyanobenzene \\
\hline $4 \mathrm{CzBz}$ & 1,2,3,5-tetrakis(carbazol-9-yl)-benzene \\
\hline 4CzTPN & 1,2,4,5-tetrakis(carbazol-9-yl)-3,6-dicyanobenzene \\
\hline CzMID & 4-carbazolyl-2-methylisoindole-1,3-dione \\
\hline
\end{tabular}

the calculated value of $\Delta \epsilon_{\mathrm{r}, \mathrm{vibr}}$ is approximately $40 \%$ smaller than the experimental value. In view of the strong (inverse quadradic) sensitivity of the effect to the energy of vibrations in the $\mathrm{THz}$ range and a possible reduction of the effect due to thermal fluctuations, we nevertheless regard this result as very encouraging. When overviewing the entire set of materials for which experimental data are available, we find a rather poor correlation between theory and experiment. We ascribe that in part to the large uncertainty of the experimental data and in part to limitations in the calculational scheme used in this paper, which neglects intermolecular interactions. Future experimental work should include more accurate determinations of the difference between the static and optical dielectric constant and studies for many more materials of the IR activity of low-energy modes using terahertz spectroscopy, in all cases measured in relation to the deposition conditions and as a function of the temperature. Future theoretical work should include a study of the effect of intermolecular interactions on the IR response, in relation to the thin-film packing and molecular orientation distribution, and a refined treatment (beyond the Clausius-Mossotti approach) of the effect of the induced electronic and vibrational polarization on nearby molecules.
As discussed in the Introduction, the dielectric permittivity sensitively affects the space-charge limited current density, the exciton formation, and dissociation rates and the singlet-triplet splitting in TADF OLEDs. Establishing an experimentally validated picture of the frequency-resolved dielectric permittivity, and its dependence on the deposition and postdeposition conditions, will furthermore provide deepened understanding of the structural stability of OLEDs materials. We regard this paper as a first systematic step toward that goal.

\section{ACKNOWLEDGMENT}

We thank Prof. R. J. Holmes for making experimental data on the optical refractive index of UGH2 and 4P-NPB available to us.

\section{APPENDIX: FULL NAMES OF THE MATERIALS STUDIED}

Table II gives an overview of the full names of the materials studied in this paper.
[1] N. F. Mott and R. W. Gurney, Electronic Processes in Ionic Crystals, 1st ed. (Oxford University Press, Oxford, 1940).

[2] P. W. M. Blom and M. C. J. M. Vissenberg, Mater. Sc. Eng. 27, 53 (2000).

[3] M. Mesta, M. Carvelli, R. J. de Vries, H. vanEersel, J. J. M. van der Holst, M. Schober, M. Furno, B. Lüssem, K. Leo, P.
Loebl, R. Coehoorn, and P. A. Bobbert, Nat. Mater. 12, 652 (2013).

[4] M. A. B. P. Kotadiya, N. B. D. Andrienko, and G.-J. A. Wetzelaer, Nat. Mater. 18, 1182 (2019).

[5] R. Coehoorn (unpublished).

[6] P. Mark and W. Helfrich, J. Appl. Phys. 33, 205 (1962). 
[7] W. Brütting, J. Frischeisen, T. D. Schmidt, B. J. Scholz, and C. Mayr, Phys. Status Solidi A 210, 44 (2013).

[8] S. J. Strickler and R. A. Berg, J. Chem. Phys. 37, 814 (1962).

[9] T. Förster, Ann. der Phys. 437, 55 (1948).

[10] S. Torabi, F. Jahani, I. Van Severen, C. Kanimozhi, S. Patil, R. W. A. Havenith, R. C. Chiechi, L. Lutsen, D. J. M. Vanderzande, T. J. Cleij, J. C. Hummelen, and L. J. A. Koster, Adv. Funct. Mater. 25, 150 (2015).

[11] M. P. Hughes, K. D. Rosenthal, R. R. Dasari, B. R. Luginbuhl, B. Yurash, S. R. Marder, and T.-Q. Nguyen, Adv. Funct. Mater. 29, 1901269 (2019).

[12] F. G. Celii, T. B. Harton, and O. F. Phillips, J. Electr. Mater. 26, 366 (1997).

[13] A. Djurisic, C. Kwong, W. Guo, T. Lau, E. Li, Z. Liu, H. Kwok, L. Lam, and W. Chan, Thin Sol. Films 416, 233 (2002).

[14] W. Xie, Y. Zhao, J. Hou, and S. Liu, Jap. J. Appl. Phys. Part 1 42, 1466 (2003)

[15] E. Hartmann, P. Boher, C. Defranoux, L. Jolivet, and M.-O. Martin, J. Lumin. 110, 407 (2004).

[16] Z. Liu, C. Kwong, C. Cheung, A. Djurišić, Y. Chan, and P. Chui, Synth. Met. 150, 159 (2005).

[17] C. Cheung, A. Djurisic, C. Kwong, J. Chan, A. Rakic, H. Tam, K. Cheah, Z. Liu, W. Chan, and P. Chui, Thin Sol. Films 489, 235 (2005).

[18] O. D. Gordan, S. Hermann, M. Friedrich, and D. R. T. Zahn, Phys. Status Solidi B 242, 2688 (2005).

[19] C. Himcinschi, N. Meyer, S. Hartmann, M. Gersdorff, M. Friedrich, H.-H. Johannes, W. Kowalsky, M. Schwambera, G. Strauch, M. Heuken, and D. Zahn, Appl. Phys. A 80, 551 (2005).

[20] C. Himcinschi, O. Gordan, G. Salvan, F. Müller, D. R. Zahn, C. Cobet, N. Esser, and W. Braun, Appl. Phys. Lett. 86, 111907 (2005).

[21] W. Holzer, A. Penzkofer, and T. Tsuboi, Chem. Phys. 308, 93 (2005).

[22] S. Hermann, O. D. Gordan, M. Friedrich, and D. R. T. Zahn, Phys. Status Solidi C 2, 4037 (2005).

[23] P. Dalasiński, Z. Łukasiak, M. Wojdyła, M. Resbarz, and W. Bała, Opt. Mater. 28, 98 (2006).

[24] L. Ding, C. Himcinschi, M. Friedrich, and D. R. T. Zahn, Phys. Status Solidi C 7, 312 (2010).

[25] L. Chen, J. Deng, H. Gao, Q. Yang, L. Kong, M. Cui, and Z. Zhang, Appl. Surf. Sci. 388, 396 (2016).

[26] H. Shin, J.-H. Lee, C.-K. Moon, J.-S. Huh, B. Sim, and J.-J. Kim, Adv. Mater. 28, 4920 (2016).

[27] M. Knupfer, Appl. Phys. A 94, 31 (2009).

[28] P. K. Nayak and N. Periasamy, Organ. Electron. 10, 532 (2009).

[29] H. Sun, Z. Hu, C. Zhong, X. Chen, Z. Sun, and J.-L. Brédas, J. Phys. Chem. Lett. 8, 2393 (2017).

[30] R. L. Martin, J. D. Kress, I. H. Campbell, and D. L. Smith, Phys. Rev. B 61, 15804 (2000).

[31] S. Berleb, W. Brütting, and G. Paasch, Org. Electron. 1, 41 (2000).

[32] Y. Xu, Y. Tao, H. Zhang, X. Chen, G. Cao, Z. Xu, H. Li, S. Bao, and P. He, Phys. B: Cond. Matter 362, 35 (2005).

[33] S. L. M. van Mensfoort, V. Shabro, R. J. de Vries, R. A. J. Janssen, and R. Coehoorn, J. Appl. Phys. 107, 113710 (2010).

[34] T. Matsushima, G.-H. Jin, Y. Kanai, T. Yokota, S. Kitada, T. Kishi, and H. Murata, Organ. Electr. 12, 520 (2011).
[35] Y. Noguchi, Y. Miyazaki, Y. Tanaka, N. Sato, Y. Nakayama, T. D. Schmidt, W. Brütting, and H. Ishii, J. Appl. Phys. 111, 114508 (2012).

[36] Y. Noguchi, H. Lim, T. Isoshima, E. Ito, M. Hara, W. Won Chin, J. Wook Han, H. Kinjo, Y. Ozawa, Y. Nakayama, and H. Ishii, Appl. Phys. Lett. 102, 203306 (2013).

[37] X.-W. Zhang, B.-J. Mo, L.-M. Liu, H.-H. Wang, D.-T. Chang, J.-W. Xu, H. Wang, and B. Wei, Curr. Appl. Phys. 14, 1460 (2014).

[38] X. Zhang, B. Mo, F. You, X. Zhou, L. Liu, H. Wang, and B. Wei, Phys. Stat. Sol. (RRL) 9, 353 (2015).

[39] F. Liu, A. Massé, P. Friederich, F. Symalla, R. Nitsche, W. Wenzel, R. Coehoorn, and P. A. Bobbert, Appl. Phys. Lett. 109, 243301 (2016).

[40] F. Kremer and A. E. Schönhals, Broadband Dielectric Spectroscopy (Springer Verlag, Berlin, 2003).

[41] H. C. F. Martens, H. B. Brom, and P. W. M. Blom, Phys. Rev. B 60, R8489 (1999).

[42] C. F. Madigan and V. Bulović, Phys. Rev. Lett. 91, 247403 (2003).

[43] M. Delor, D. G. McCarthy, B. L. Cotts, T. D. Roberts, R. Noriega, D. D. Devore, S. Mukhopadhyay, T. S. De Vries, and N. S. Ginsberg, J. Phys. Chem. Lett. 8, 4183 (2017).

[44] G. Méhes, K. Goushi, W. J. Potscavage, and C. Adachi, Organ. Electr. 15, 2027 (2014).

[45] C. Deng, L. Zhang, D. Wang, T. Tsuboi, and Q. Zhang, Adv. Optical Mater. 7, 1801644 (2019)

[46] V. Bulovic, A. Shoustikov, M. Baldo, E. Bose, V. Kozlov, M. Thompson, and S. Forrest, Chem. Phys. Lett. 287, 455 (1998).

[47] V. Bulovic, R. Deshpande, M. Thompson, and S. Forrest, Chemi. Phys. Lett. 308, 317 (1999).

[48] Z. Tu, G. Han, T. Hu, R. Duan, and Y. Yi, Chem. Mater. 31, 6665 (2019)

[49] H. Hikawa, M. Oguni, and H. Suga, J. Non-Cryst. Sol. 101, 90 (1988).

[50] C. A. Angell, Science 267, 1924 (1995).

[51] J. Ràfols-Ribé, P.-A. Will, C. Hänisch, M. Gonzalez-Silveira, S. Lenk, J. Rodríguez-Viejo, and S. Reineke, Sci. Adv. 4, eaar8332 (2018).

[52] J. D. Jackson, Classical Electrodynamics, 2nd ed. (John Wiley \& Sons, New York, 1975).

[53] See Supplemental Material at https://link.aps.org/ supplemental/10.1103/PhysRevMaterials.4.085602 for a derivation of Eq. (2) using the Lorentz oscillator model, an analysis for NPB of the effect of the basis set on the calculated vibrational contribution to $\Delta \epsilon_{\mathrm{r}, \mathrm{vibr}}$, calculational results for $\mathrm{C}_{60}$ and all-trans retinal, an overview of the correlation of $\Delta \epsilon_{\mathrm{r}, \mathrm{vibr}}$ with various other quantities, and a comparison between NPB and TPD.

[54] A. Aubret, M. Orrit, and F. Kulzer, ChemPhysChem 20, 343 (2019).

[55] M. R. Pederson, T. Baruah, P. B. Allen, and C. Schmidt, J. Chem. Theory Comput. 1, 590 (2005).

[56] R. R. Zope, T. Baruah, M. R. Pederson, and B. I. Dunlap, Int. J. Quant. Chem. 108, 307 (2008).

[57] R. R. Zope, J. Phys. B: At. Mol. Opt, Phys. 40, 3491 (2007).

[58] R. R. Zope, T. Baruah, M. R. Pederson, and B. I. Dunlap, Phys. Rev. B 77, 115452 (2008).

[59] H. Takagishi, T. Masuda, T. Shimoda, R. Maezono, and K. Hongo, J. Phys. Chem. A 123, 8726 (2019). 
[60] D. M. Wilkins, A. Grisafi, Y. Yang, K. U. Lao, R. A. DiStasio, and M. Ceriotti, Proc. Natl. Acad. Sc. 116, 3401 (2019).

[61] L. K. W. D. Yang, Y. A. Grisafi, M. Ceriotti, and R. DiStasio, Jr., Sci. Data 6, 152 (2019).

[62] A. D. Becke, J. Chem. Phys. 98, 1372 (1993).

[63] D. A. Pantazis, X.-Y. Chen, C. R. Landis, and F. Neese, J. Chem. Theory Comput. 4, 908 (2008).

[64] T. Lu and F. Chen, J. Comput. Chem. 33, 580 (2012).

[65] H.-F. Xiang, Z.-X. Xu, V. A. L. Roy, C.-M. Che, and P. T. Lai, Rev. Sci. Instrum. 78, 034104 (2007).

[66] M. D. Halls, C. P. Tripp, and H. B. Schlegel, Phys. Chem. Chem. Phys. 3, 2131 (2001).

[67] J. Neugebauer, M. Reiher, C. Kind, and B. A. Hess, J. Comput. Chem. 23, 895 (2002).

[68] F. Neese, J. Chem. Phys. 122, 034107 (2005).

[69] F. Neese, Wiley Interdiscip. Rev. Comput. Mol. Sci. 8, 4 (2018).

[70] A. P. Scott and L. Radom, J. Phys. Chem. 100, 16502 (1996).

[71] G. Chern, H. Mathias, L. R. Testardi, L. Seger, and J. Schlenoff, J. of Supercond. 8, 207 (1995).

[72] H. Kuzmany, R. Winkler, and T. Pichler, J. Phys.: Cond. Matt. 7, 6601 (1995).

[73] D. Porezag and M. R. Pederson, Phys. Rev. B 54, 7830 (1996).

[74] S. Iglesias-Groth, F. Cataldo, and A. Manchado, Mon. Not. R. Astron. Soc. 413, 213 (2011).

[75] F. L. Gervasio, G. Cardini, P. R. Salvi, and V. Schettino, J. Phys. Chem. A 102, 2131 (1998).

[76] M. Walther, B. Fischer, M. Schall, H. Helm, and P. U. Jepsen, Chem. Phys. Lett. 332, 389 (2000).

[77] C. Han, Y. Zhao, H. Xu, J. Chen, Z. Deng, D. Ma, Q. Li, and P. Yan, Chem. - Eur. J. 17, 5800 (2011).

[78] K. S. Yook and J. Y. Lee, Org. Electr. 12, 1293 (2011).

[79] S. Youn Lee, T. Yasuda, H. Nomura, and C. Adachi, Appl. Phys. Lett. 101, 093306 (2012).

[80] R. J. Holmes, B. W. D’Andrade, S. R. Forrest, X. Ren, J. Li, and M. E. Thompson, Appl. Phys. Lett. 83, 3818 (2003).

[81] S.-Y. Takizawa, V. A. Montes, and P. Anzenbacher, Chem. Mater. 21, 2452 (2009).

[82] M. A. Baldo, S. Lamansky, P. E. Burrows, M. E. Thompson, and S. R. Forrest, Appl. Phys. Lett. 75, 4 (1999).

[83] T. Aimono, Y. Kawamura, K. Goushi, H. Yamamoto, H. Sasabe, and C. Adachi, Appl. Phys. Lett. 86, 071110 (2005).
[84] A. S. D. Sandanayaka, T. Matsushima, F. Bencheikh, S. Terakawa, W. J. Potscavage, C. Qin, T. Fujihara, K. Goushi, J.-C. Ribierre, and C. Adachi, Appl. Phys. Expr. 12, 061010 (2019).

[85] C. W. Tang and S. A. VanSlyke, Appl. Phys. Lett. 51, 913 (1987).

[86] H. Uoyama, K. Goushi, K. Shizu, H. Nomura, and C. Adachi, Nature 492, 234 (2012).

[87] H. Nakanotani, K. Masui, J. Nishide, T. Shibata, and C. Adachi, Sci. Rep. 3, 2127 (2013).

[88] C. Peng, A. Salehi, Y. Chen, M. Danz, G. Liaptsis, and F. So, ACS Appl. Mater. Interfaces 9, 41421 (2017).

[89] J. Jiang, D. M. Walters, D. Zhou, and M. D. Ediger, Soft Matter 12, 3265 (2016).

[90] S. S. Dalal, D. M. Walters, I. Lyubimov, J. J. de Pablo, and M. D. Ediger, Proc. Natl. Acad. Sci. 112, 4227 (2015).

[91] M. Rajeswaran, T. N. Blanton, C. W. Tang, W. C. Lenhart, S. C. Switalski, D. J. Giesen, B. J. Antalek, T. D. Pawlik, D. Y. Kondakov, N. Zumbulyadis, and R. H. Young, Polyhedron 28, 835 (2009).

[92] S.-Y. Hung, R.-L. Kao, K.-Y. Lin, C.-C. Yang, K.-S. Lin, Y.-C. Chao, J.-S. Wang, J.-L. Shen, and K.-C. Chiu, Mater. Chem. Phys. 154, 100 (2015).

[93] B. M. Fischer, M. Walther, and P. U. Jepsen, Phys. Med. Biol. 47, 3807 (2002).

[94] M. Franz, B. M. Fischer, and M. Walther, J. Molec. Struct. 1006, 34 (2011).

[95] P. Friederich, V. Rodin, F. von Wrochem, and W. Wenzel, ACS Appl. Mater. Interfaces 10, 1881 (2018).

[96] B. Bernardo, D. Cheyns, B. Verreet, R. Schaller, B. Rand, and N. Giebink, Nat. Commun. 5, 3245 (2014).

[97] D. Yokoyama, A. Sakaguchi, M. Suzuki, and C. Adachi, Appl. Phys. Lett. 93, 173302 (2008)

[98] R. J. Holmes (private communication).

[99] Y. Watanabe, H. Sasabe, D. Yokoyama, T. Beppu, H. Katagiri, Y.-J. Pu, and J. Kido, Adv. Opt. Mater. 3, 769 (2015).

[100] D. Yokoyama and C. Adachi, J. Appl. Phys. 107, 123512 (2010).

[101] S. L. Ren, Y. Wang, A. M. Rao, E. McRae, J. M. Holden, T. Hager, K. Wang, W. Lee, H. F. Ni, J. Selegue, and P. C. Eklund, Appl. Phys. Lett. 59, 2678 (1991). 